\title{
Hepatocyte Nuclear Factor 4-Alpha Hyperinsulinism
}

National Cancer Institute

\section{Source}

National Cancer Institute. Hepatocyte Nuclear Factor 4-Alpha Hyperinsulinism. NCI

Thesaurus. Code C131834.

Hyperinsulinism due to mutation(s) in the gene HNF4A, encoding the transcription factor hepatocyte nuclear factor 4-alpha. This condition may progress to diabetes later in life. 